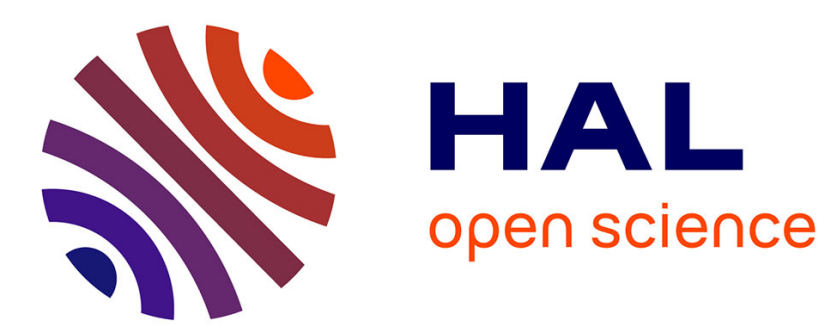

\title{
Interpretation of clinical guidelines for poisoned patients: positive and negative effects of standard phrases used in TOXBASE
}

\author{
W. S. Waring, S. H. Mcdonald, A. M. Good, L. D. Gordon, D. N. Bateman
}

\section{- To cite this version:}

W. S. Waring, S. H. Mcdonald, A. M. Good, L. D. Gordon, D. N. Bateman. Interpretation of clinical guidelines for poisoned patients: positive and negative effects of standard phrases used in TOXBASE. European Journal of Clinical Pharmacology, 2009, 65 (10), pp.1007-1012. 10.1007/s00228-009-06699. hal-00534967

\section{HAL Id: hal-00534967 https://hal.science/hal-00534967}

Submitted on 11 Nov 2010

HAL is a multi-disciplinary open access archive for the deposit and dissemination of scientific research documents, whether they are published or not. The documents may come from teaching and research institutions in France or abroad, or from public or private research centers.
L'archive ouverte pluridisciplinaire HAL, est destinée au dépôt et à la diffusion de documents scientifiques de niveau recherche, publiés ou non, émanant des établissements d'enseignement et de recherche français ou étrangers, des laboratoires publics ou privés. 


\title{
Interpretation of clinical guidelines for poisoned patients: positive and negative effects of standard phrases used in TOXBASE
}

\author{
W. S. Waring • S. H. McDonald • A. M. Good • \\ L. D. Gordon • D. N. Bateman
}

Received: 30 January 2009 /Accepted: 16 May 2009 /Published online: 11 June 2009

(C) Springer-Verlag 2009

\begin{abstract}
Introduction Electronic information sources are increasingly relied upon for clinical management advice. TOXBASE is a standardised online resource that offers clinical advice on the management of poisoned patients and is the first point of contact between clinicians and the National Poisons Information Service in the United Kingdom. Advice is delivered using a series of standard phrases. The present study examined how healthcare professionals interpret the phrases and studied their impact on clinical decision-making.

Methods A structured prospective written questionnaire was offered to healthcare staff in the Lothian region, and an electronic questionnaire issued to TOXBASE users across the United Kingdom. Participants were asked to respond to a variety of scenarios representing acutely poisoned patients. Clinical management advice was offered via TOXBASE using a variety of standard phrases, and participants were asked to express the likelihood that they would then administer gut decontamination treatment.

Results There were 70 respondents to written questionnaires, and 119 respondents to the electronic version. Phrases that included didactic instructions, for example 'give', 'contraindicated', 'do' and 'perform' were associated with strongly positive or strongly negative responses. In contrast, advice that consisted of open phrases such as 'consider', 'benefit uncertain', and 'few data' were associated with inconsistent responses.
\end{abstract}

W. S. Waring $\cdot$ S. H. McDonald · A. M. Good $\cdot$ L. D. Gordon

D. N. Bateman $(\bowtie)$

NPIS Edinburgh, Scottish Poisons Information Bureau,

The Royal Infirmary of Edinburgh,

51 Little France Crescent,

Edinburgh EH16 4SA, UK

e-mail: nick.bateman@1uht.scot.nhs.uk
Conclusion Didactic words and phrases are associated with more consistent interpretation and response than open-ended words and phrases. The choice of words and phrases used in electronic systems can have an independent impact on clinical decision-making and require further consideration.

Keywords Electronic decision support · Guidelines · Poisoning · Overdose · Questionnaire · TOXBASE

\section{Introduction}

TOXBASE is an electronic database that contains advice concerning the clinical management of poisoned patients and includes details of approximately 14,000 pharmaceutical products and chemicals [1]. There are entries for special patient groups, for example poisoning in paediatric and pregnant patients, decontamination procedures, explanations of slang terminology, and priority health warnings. TOXBASE is freely accessible to registered healthcare staff and is available in most Emergency Departments and critical-care units across the United Kingdom and Ireland. The entries are written and regularly updated by the National Poisons Information Service (NPIS), and there is a supporting telephone service for enquiries that are not addressed by TOXBASE alone, for example after complex multiple-drug ingestion [2].

TOXBASE uses a structured format to provide details of the type of product, toxicity and clinical features, and recommended patient management. Entries are productspecific but, where possible, the clinical management advice uses a number of standard phrases that have been agreed upon by the directors of the NPIS Poisons Units [3]. For example, standard phrases are used concerning the dose and route of administration of oral-activated charcoal, management of drug-related hypotension, and management of hyperthermia. 


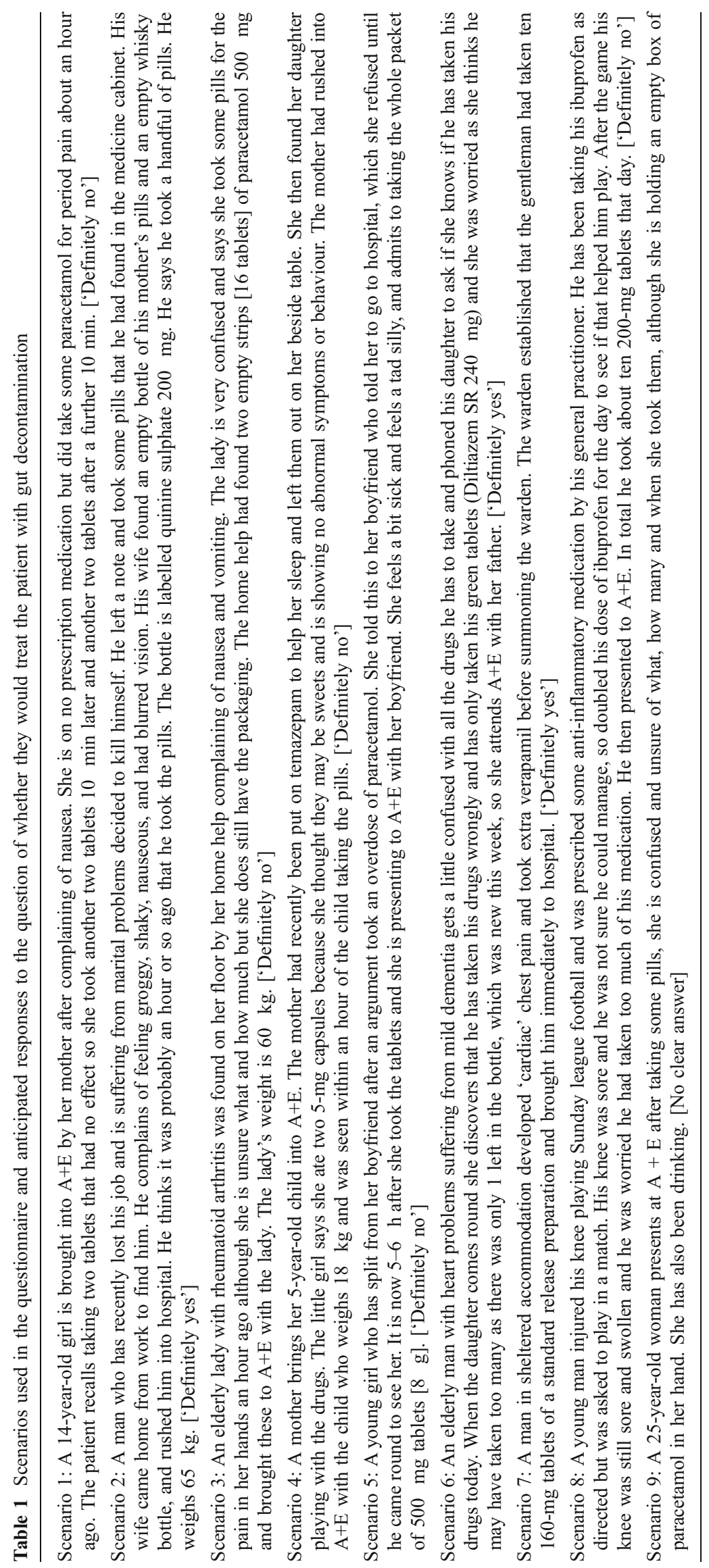


The Department of Health policy is that TOXBASE should be relied on as the primary source of poisoning management advice in the United Kingdom and, for example, there were more than 400,000 accesses in 2007. Few data are available concerning interpretation of TOXBASE entries by healthcare staff, and this might have an important impact on the utility of an electronic source of clinical advice. The present study was designed to examine how TOXBASE users interpret the form of words used in standard phrases, and whether this has an impact on the decision to administer or not to administer gut decontamination treatment.

\section{Methods}

Gut decontamination is associated with a broader evidence base than other aspects of clinical toxicology and is informed by international guidelines and expert position statements [4-6]. There are seven standard phrases concerning aspects of gastric decontamination in TOXBASE. Written questionnaires were designed to examine interpretation of these standard phrases in a series of clinical scenarios and the likelihood that healthcare staff would interpret the phrases in the manner intended by the NPIS in accordance with the international joint position papers (Table 1). Questionnaires were posted to 225 healthcare staff working in the Emergency Department and Acute Medical Unit of hospitals in the Lothian University Hospitals NHS Trust, including nursing staff, final-year medical students, and junior and senior medical staff, and responses ascertained during a 10-week period in 2007.

Respondent data collected were age, job role, department, and previous experience of using TOXBASE. Participants were then asked to study nine separate clinical scenarios and corresponding TOXBASE advice, and respond in the following terms to whether they would treat the patient with gut decontamination: 'definitely yes', 'probably yes', 'possibly yes', 'possibly no', 'probably no', or 'definitely no'. In eight of these, there was a predetermined correct answer, and a 'definitely yes' or 'definitely no' was anticipated. Minimal clinical data were provided, reflecting the scenarios commonly encountered in clinical practice. Whereas in a realistic clinical setting one might be expected to make a definite 'yes' or 'no' decision, a broader range of responses were studied in order to ascertain the certainty of interpretation in a graded manner. One scenario was not associated with a correct answer and was used to assess marker response bias. Participants were then asked to evaluate paraphrases extracted from the standard phrases and to report whether these would motivate them to administer activated charcoal such as 'definitely would', 'probably would', 'don't know', 'probably would not', or 'definitely would not'.

A follow-up study involved distribution of electronic questionnaires to 4,722 registered TOXBASE users. Participants were asked to respond to the effect of the paraphrases, as described above, and to submit their responses electronically.

\section{Data analyses}

Data are presented as median and interquartile ranges. The null hypothesis was correct response rate $=50 \%$, and the significance of obtaining a correct response was determined using $F$-tests. Responses were compared between different staff groups, departments, and prior experience of TOXBASE using chi-squared proportional tests using MedCalc (version 9.0.1.1; MedCalc, Mariakerke, Belgium) [7, 8].

Table 2 Absolute number of responses, and percentage of all responders

\begin{tabular}{|c|c|c|c|c|c|c|c|c|c|}
\hline & $\begin{array}{l}\text { Anticipated } \\
\text { answer }\end{array}$ & Definitely yes & Probably yes & Possibly yes & Possibly no & Probably no & Definitely no & $\%$ AAA & $\begin{array}{l}\text { Overall } \\
P \text { value }\end{array}$ \\
\hline 1 & No & $1(1 \%)$ & $2(3 \%)$ & $3(4 \%)$ & $2(3 \%)$ & $35(50 \%)$ & $27(39 \%)$ & $27(39 \%)$ & $<0.0001$ \\
\hline 2 & Yes & $23(34 \%)$ & $25(38 \%)$ & $12(18 \%)$ & $1(2 \%)$ & $4(6 \%)$ & $2(3 \%)$ & $23(34 \%)$ & $<0.0001$ \\
\hline 3 & No & $2(3 \%)$ & $18(27 \%)$ & $16(24 \%)$ & $5(7 \%)$ & $21(31 \%)$ & $6(9 \%)$ & $6(9 \%)$ & 0.6278 \\
\hline 4 & No & $0(0 \%)$ & $2(3 \%)$ & $2(3 \%)$ & $1(2 \%)$ & $17(25 \%)$ & $46(68 \%)$ & $46(68 \%)$ & $<0.0001$ \\
\hline 5 & No & $3(5 \%)$ & $1(2 \%)$ & $5(8 \%)$ & $0(0 \%)$ & $10(15 \%)$ & $46(71 \%)$ & $46(71 \%)$ & $<0.0001$ \\
\hline 6 & Yes & $0(0 \%)$ & $7(11 \%)$ & $16(25 \%)$ & $2(3 \%)$ & $29(45 \%)$ & $11(17 \%)$ & $0(0 \%)$ & 0.0184 \\
\hline 7 & Yes & $7(11 \%)$ & $22(33 \%)$ & $17(26 \%)$ & $7(11 \%)$ & $7(11 \%)$ & $6(9 \%)$ & $7(11 \%)$ & 0.0014 \\
\hline 8 & No & $1(2 \%)$ & $0(0 \%)$ & $1(2 \%)$ & $3(5 \%)$ & $23(35 \%)$ & $37(57 \%)$ & $37(57 \%)$ & $<0.0001$ \\
\hline 9 & None & $3(5 \%)$ & $8(12 \%)$ & $15(23 \%)$ & $4(6 \%)$ & $25(39 \%)$ & $10(15 \%)$ & - & - \\
\hline
\end{tabular}

$A A A$ Answered as anticipated (yes or no).

$P$-values represent the likelihood that the correct answer (yes versus no) was obtained by chance by $F$-test compared to the null hypothesis (correct response $=50 \%)$ 


\section{Results}

Seventy written questionnaires were returned, and 59 were completed in full, representing a $31 \%$ response rate and $84 \%$ completion rate respectively. Electronic questionnaires were completed and submitted by 119 respondents.

Responses to the scenarios

The anticipated response and actual responses to each of the nine scenarios are presented in Table 2. A high proportion of respondents interpreted the guidance correctly in scenarios 4 , 5 and $9(68,71$ and $80 \%$ respectively), and these were regarded as examples of effective language. In contrast, an unexpectedly low proportion of respondents correctly interpreted the guidance offered in scenarios 3, 6 and 7 (9, 0 and
$11 \%$ respectively), and these were regarded as examples of ambiguous language.

Responses to specific phrases and words

Responses to specific phrases and individual words in the written and electronic questionnaires are presented in Tables 3 and 4 respectively. Phrases and words that prompted a positive response ('positive phrases') were 'consider', 'give', 'perform', and 'evidence'. Conversely, certain phrases and words by themselves deterred respondents from offering treatment ('negative phrases'), which were 'uncertain', 'no evidence', 'too late', and 'do not'. These positive and negative phrases had a discernible impact on the likelihood that respondents might or might not administer oral-activated charcoal.

Table 3 Effect of specific phrases and words on the likelihood that responders would administer activated charcoal, as absolute number and percentage of all responders to the written questionnaire $(n=70)$

\begin{tabular}{|c|c|c|c|c|c|}
\hline Phrase & $\begin{array}{l}\text { Definitely } \\
\text { wouldn't }\end{array}$ & $\begin{array}{l}\text { Probably } \\
\text { wouldn’t }\end{array}$ & Don’t know & $\begin{array}{l}\text { Probably } \\
\text { would }\end{array}$ & $\begin{array}{l}\text { Definitely } \\
\text { would }\end{array}$ \\
\hline 'The benefit of gastric decontamination is uncertain.' & $2(3.1 \%)$ & $41(63.1 \%)$ & $15(23.1 \%)$ & $7(10.8 \%)$ & $0(0.0 \%)$ \\
\hline $\begin{array}{l}\text { 'Consider activated charcoal if more than } \\
\mathrm{X} \text { dose has been taken' }\end{array}$ & $0(0.0 \%)$ & $5(7.7 \%)$ & $12(18.5 \%)$ & $37(56.9 \%)$ & $11(16.9 \%)$ \\
\hline $\begin{array}{l}\text { 'Consider repeated doses of activated charcoal } \\
\text { provided that the patient is not vomiting and the } \\
\text { airway can be protected.' }\end{array}$ & $0(0.0 \%)$ & $5(7.7 \%)$ & $17(26.2 \%)$ & $35(53.8 \%)$ & $8(12.3 \%)$ \\
\hline $\begin{array}{l}\text { 'Consider gastric lavage in potentially life } \\
\text { threatening overdose.' }\end{array}$ & $12(18.2 \%)$ & $4(6.1 \%)$ & $13(19.7 \%)$ & $19(28.8 \%)$ & $18(27.3 \%)$ \\
\hline $\begin{array}{l}\text { 'Although it may seem reasonable to assume, } \\
\text { there is no evidence to support this.' }\end{array}$ & $12(18.5 \%)$ & $27(41.5 \%)$ & $14(21.5 \%)$ & $12(18.5 \%)$ & $0(0.0 \%)$ \\
\hline 'There is no evidence to support this.' & $32(49.2 \%)$ & $21(32.3 \%)$ & $10(15.4 \%)$ & $2(3.1 \%)$ & $0(0.0 \%)$ \\
\hline $\begin{array}{l}\text { 'Although it may seem reasonable to assume } \\
\text { that late administration of activated charcoal } \\
\text { may be beneficial for preparations which delay } \\
\text { gastric emptying there are few data to support this.' }\end{array}$ & $10(15.4 \%)$ & $30(46.2 \%)$ & $10(15.4 \%)$ & $14(21.5 \%)$ & $1(1.5 \%)$ \\
\hline 'It is too late for gastric decontamination.' & $55(84.6 \%)$ & $6(9.2 \%)$ & $2(3.1 \%)$ & $1(1.5 \%)$ & $1(1.5 \%)$ \\
\hline 'There are few data to support this.' & $17(26.2 \%)$ & $36(55.4 \%)$ & $10(15.4 \%)$ & $2(3.1 \%)$ & $0(0.0 \%)$ \\
\hline $\begin{array}{l}\text { 'There are no controlled trials which } \\
\text { demonstrate benefit in evidence.' }\end{array}$ & $17(26.2 \%)$ & $32(49.2 \%)$ & $11(16.9 \%)$ & $5(7.7 \%)$ & $0(0.0 \%)$ \\
\hline $\begin{array}{l}\text { 'Evidence in volunteers suggests it may } \\
\text { increase the elimination of...' }\end{array}$ & $1(1.6 \%)$ & $5(7.8 \%)$ & $21(32.8 \%)$ & $36(56.3 \%)$ & $1(1.6 \%)$ \\
\hline \multicolumn{6}{|l|}{ Specific words } \\
\hline 'Uncertain’ & $4(6.2 \%)$ & $42(64.6 \%)$ & $13(20.0 \%)$ & $8(9.2 \%)$ & $0(0.0 \%)$ \\
\hline 'Give' & $0(0.0 \%)$ & $0(0.0 \%)$ & $4(6.2 \%)$ & $24(36.9 \%)$ & $37(56.9 \%)$ \\
\hline 'Perform' & $1(1.6 \%)$ & $1(1.6 \%)$ & $23(35.9 \%)$ & $20(31.3 \%)$ & $19(29.7 \%)$ \\
\hline ‘Do’' & $0(0.0 \%)$ & $0(0.0 \%)$ & $6(9.2 \%)$ & $24(36.9 \%)$ & $35(53.8 \%)$ \\
\hline 'Do not' & $52(80.0 \%)$ & $7(10.8 \%)$ & $3(4.6 \%)$ & $0(0.0 \%)$ & $3(4.6 \%)$ \\
\hline 'Consider' & $1(1.5 \%)$ & $11(16.9 \%)$ & $22(33.8 \%)$ & $29(44.6 \%)$ & $2(3.1 \%)$ \\
\hline 'No evidence' & $25(38.5 \%)$ & $32(49.2 \%)$ & $5(7.7 \%)$ & $3(4.6 \%)$ & $0(0.0 \%)$ \\
\hline 'Benefit uncertain' & $4(6.3 \%)$ & $38(59.4 \%)$ & $12(18.8 \%)$ & $10(15.6 \%)$ & $0(0.0 \%)$ \\
\hline 'Few data' & $9(13.8 \%)$ & $35(53.8 \%)$ & $13(20.0 \%)$ & $8(12.3 \%)$ & $0(0.0 \%)$ \\
\hline 'No data' & $27(41.5 \%)$ & $27(41.5 \%)$ & $7(10.8 \%)$ & $4(6.2 \%)$ & $0(0.0 \%)$ \\
\hline 'Too late' & $60(92.3 \%$ & $4(6.2 \%)$ & $1(1.5 \%)$ & $0(0.0 \%)$ & $0(0.0 \%)$ \\
\hline
\end{tabular}


Table 4 Effect of specific phrases on the likelihood that responders would pursue a particular clinical intervention, absolute number and percentage of all responders to the electronic questionnaire $(n=119)$

\begin{tabular}{llllll}
\hline Phrase & Definitely wouldn't & Probably wouldn't & Don't know & Probably would & Definitely would \\
\hline 'Uncertain' & $11(9.2 \%)$ & $53(44.5 \%)$ & $44(37.0 \%)$ & $11(9.2 \%)$ & $0(0.0 \%)$ \\
'Few data' & $3(2.5 \%)$ & $47(39.5 \%)$ & $56(47.1 \%)$ & $13(10.9 \%)$ & $0(0.0 \%)$ \\
'Do' & $2(1.7 \%)$ & $0(0.0 \%)$ & $2(1.7 \%)$ & $20(16.9 \%)$ & $94(79.9 \%)$ \\
'Too late' & $61(51.3 \%)$ & $47(39.5 \%)$ & $8(6.7 \%)$ & $2(1.7 \%)$ & $1(0.8 \%)$ \\
'No evidence' & $32(26.9 \%)$ & $50(42.0 \%)$ & $28(23.5 \%)$ & $8(6.7 \%)$ & $1(0.8 \%)$ \\
'Give' & $3(2.5 \%)$ & $0(0.0 \%)$ & $2(1.7 \%)$ & $22(18.5 \%)$ & $92(77.3 \%)$ \\
'No data' & $26(21.8 \%)$ & $49(41.2 \%)$ & $35(29.4 \%)$ & $9(7.6 \%)$ & $0(0.0 \%)$ \\
'Benefit uncertain' & $4(3.4 \%)$ & $55(46.2 \%)$ & $41(34.9 \%)$ & $19(16.0 \%)$ & $0(0.0 \%)$ \\
'Do not' & $110(92.4 \%)$ & $4(3.4 \%)$ & $0(0.0 \%)$ & $0(0.0 \%)$ & $5(4.2 \%)$ \\
'Perform' & $2(1.7 \%)$ & $0(0.0 \%)$ & $6(5.0 \%)$ & $20(16.8 \%)$ & $91(76.5 \%)$ \\
'Consider' & $2(1.7 \%)$ & $4(3.4 \%)$ & $17(14.4 \%)$ & $86(72.9 \%)$ & $9(7.6 \%)$ \\
'Few data to support' & $8(6.7 \%)$ & $62(52.1 \%)$ & $35(29.4 \%)$ & $14(11.8 \%)$ & $0(0.0 \%)$ \\
\hline
\end{tabular}

\section{Differences among participants}

The response to scenarios or specific phrases did not differ among groups defined by seniority, normal department, and prior experience of TOXBASE (Table 5).

\section{Discussion}

The NPIS has offered poisoning management advice to healthcare staff by telephone since the 1960s. TOXBASE was adopted as the primary source of poisons information to healthcare staff in the UK in 1999, and the number of electronic enquiries for clinical management advice has been increasing progressively. The use of ambiguous language might result in misinterpretation, and there are important implications for subsequent clinical management and patient care. The present findings indicate that the words used to convey clinical advice can have an important impact on the interpretation of standard phrases by healthcare staff and clinical decision-making concerning activated charcoal administration. Greatest consistency of responses occurred in response to phrases with concise positive and negative commands, for example 'perform', 'give', and 'do not'. These suggest a form of language that participants felt comfortable with and offered a clear instruction. This is consistent with earlier research that showed structured guidelines containing an action-type verb are associated with a higher likelihood that clinicians will perform a specific task $[9,10]$.

More subtle effects were seen with words intended to convey a neutral message with no positive or negative instruction. The word 'consider', by itself or as part of a standard phrase, actually conveyed a positive effect and healthcare staff were more likely to favour charcoal administration. In contrast, the word 'uncertain', by itself and in phrases, conveyed a negative effect and deterred respondents from administering treatment. Many of the forms of words used in the standard phrases were intended to be neutral in meaning, particularly those concerning a lack of supportive data. However, responses to phrases that included 'no evidence', 'few data', and 'no data' were interpreted in a negative manner, and deterred participants from administering activated charcoal. This effect pervaded even if combined with a positive word or paraphrase, suggesting that negative statements exert a more powerful effect overall.

Earlier reports have advocated a need for deliberate vagueness in guidelines where a clear evidence base or a consensus expert opinion is lacking [10,11]. For example, advice should be open-ended with presentation of support-

Table 5 Responses stratified by clinical grade, usual department, and previous use of TOXBASE presented as median (interquartile range) and percentage of total score available compared with the anticipated answer

\begin{tabular}{lll}
\hline Groups & Score & Percentage \\
\hline Final-year medical student & $39.5(38.0-41.0)$ & 80 \\
Nurse & $34.5(31.0-36.5)$ & 70 \\
Junior doctor & $37.5(32.5-39.8)$ & 77 \\
Senior doctor & $36.0(34.0-40.3)$ & 73 \\
Combined assessment area & $39.5(35.8-40.3)$ & 81 \\
Emergency department & $37.5(36.3-41.0)$ & 77 \\
Critical care & $35.0(32.5-36.3)$ & 71 \\
Acute medicine & $38.0(34.0-38.8)$ & 78 \\
Acute receiving unit & $36.0(32.0-40.0)$ & 73 \\
Prior TOXBASE use & $38.0(34.0-40.0)$ & 61 \\
No prior TOXBASE use & $37.0(34.0-40.0)$ & 76 \\
\hline
\end{tabular}


ing data where available to allow interpretation by the reader [10]. However, the present findings indicate a need to further examine the possibility that inclusion of particular words and phrases might confer an unintended positive or negative meaning in certain situations. Formal strategies for identification of appropriate neutral language for clinical guidelines need to be developed.

The response rates to both the written questionnaire and the subsequent electronic survey were lower than anticipated from earlier studies (31 and 2.5\% respectively) $[12,13]$. In contrast to many earlier studies involving questionnaires, the present study population was operating in an Emergency Department and Acute Medical Unit setting, and a high clinical workload might have impacted on the ability to respond. Subjective preference for written rather than electronic data format might have contributed to lower than anticipated response rates [14]. Therefore, the findings of this study might not be generalisable to a wider population of TOXBASE users. Despite this, respondent characteristics did represent a typical demographic of enquirers in terms of their work department, seniority, and prior experience of using TOXBASE. The scenarios were designed to represent the most commonly encountered types of self-poisoning that present to Emergency Departments. Use of the same drug across different scenarios was intended to minimise the effect of prior knowledge or poisoning complexity on respondent's answers. A potential limitation is that the study examined only certain standard phrases that were related to gastric decontamination, and the conclusions might not be generalisable to clinical guidelines related to other aspects of treatment. Also, the study is based on two comparatively small cohorts of TOXBASE users, and data collection was performed over a limited period. Nevertheless the consistency of response between the groups suggests a degree of commonality of approach to interpretation of language.

In conclusion, clinical guidance offered by TOXBASE and supported by international position statements was not interpreted uniformly. The language and form of words may exert an important influence on how healthcare staff interpret and respond to guidelines. Further work is needed to examine whether the use of specific words and phrases might allow a clearer interpretation of guidelines intended to support clinical decision making.

\section{Competing interests}

Several of the authors (A.M.G., D.N.B., W.S.W., L.D.G.) are members of the National Poisons Information Service, the organisation responsible for writing and editing TOXBASE guidelines. There were no specific sources of funding associated with this research.

Author's consent for publication

We the aforementioned give consent for this to be published.

\section{References}

1. Bateman DN, Good AM, Laing WJ, Kelly CA (2002) TOXBASE poisons information on the internet. Emerg Med J 19:31-34

2. Thanacoody HK, Good AM, Waring WS, Bateman DN (2008) Survey of cases of paracetamol overdose in the UK referred to National Poisons Information Service (NPIS) consultants. Emerg Med J 25:140-143

3. Bateman DN, Good AM (2006) Five years of poisons information on the internet: the UK experience of TOXBASE. Emerg Med J 23:614-617

4. Lynch RM, Robertson R (2003) Activated charcoal: the untold story. Accid Emerg Nurs 11:63-67

5. Chyka PA, Seger D, Krenzelok EP, Vale JA (2005) American Academy of Clinical Toxicology; European Association of Poisons Centres and Clinical Toxicologists. Position paper: single-dose activated charcoal. Clin Toxicol 43:61-87

6. Wall AJ, Bateman DN, Waring WS (2009) Variability in the quality of overdose advice in summary of product characteristics (SPC) documents: gut decontamination recommendations for CNS drugs. Br J Clin Pharmacol 67:83-87

7. Waring WS, Good AM, Bateman DN (2007) Lack of significant toxicity after mirtazapine overdose: a five-year review of cases admitted to a regional toxicology unit. Clin Toxicol 45:45-50

8. Waring WS, Benhalim S (2008) Serum acetaminophen concentrations after acute overdose are not altered by opioid coingestion. J Toxicol Sci 33:549-553

9. Greenes RA (2003) Decision support at the point of care: challenges in knowledge representation, management, and patient-specific access. Adv Dent Res 17:69-73

10. Rossenfeld RM, Shiffman RN (2006) Clinical practice guidelines: a manual for developing evidence-based guidelines to facilitate performance measurement and quality improvement. Otolaryngol Head Neck Surg 135:S1-S28

11. Beliakov G, Warren J (2001) Fuzzy logic for decision support in chronic care. Artif Intell Med 21:209-213

12. Indermitte J, Erba L, Beutler M, Bruppacher R, Haefeli WE, Hersberger KE (2007) Management of potential drug interactions in community pharmacies: a questionnaire-based survey in Switzerland. Eur J Clin Pharmacol 63:297-305

13. Boshier A, Wilton LV, Shakir SA (2003) Evaluation of the safety of bupropion (Zyban) for smoking cessation from experience gained in general practice use in England in 2000. Eur J Clin Pharmacol 59:767-773

14. Bergk V, Gasse C, Schnell R, Haefeli WE (2004) Requirements for a successful implementation of drug interaction information systems in general practice: results of a questionnaire survey in Germany. Eur J Clin Pharmacol 60:595-602 